\title{
Quantitative assessment of changes in surface particulate matter concentrations and precursor emissions over China during the COVID-19 pandemic and their implications for Chinese economic activity
}

\author{
Hyun Cheol Kim ${ }^{1,2}$, Soontae Kim ${ }^{3}$, Mark Cohen ${ }^{1}$, Changhan Bae ${ }^{4}$, Dasom Lee ${ }^{5, \text { a }}$, Rick Saylor ${ }^{1}$, Minah Bae $^{3}$, \\ Eunhye Kim $^{3}$, Byeong-Uk Kim ${ }^{6}$, Jin-Ho Yoon ${ }^{5}$, and Ariel Stein ${ }^{1}$ \\ ${ }^{1}$ Air Resources Laboratory, National Oceanic and Atmospheric Administration, College Park, MD, USA \\ ${ }^{2}$ Cooperative Institute for Satellite Earth System Studies, University of Maryland, College Park, MD, USA \\ ${ }^{3}$ Department of Environmental and Safety Engineering, Ajou University, Suwon, South Korea \\ ${ }^{4}$ National Air Emission Inventory and Research Center, Sejong, South Korea \\ ${ }^{5}$ School of Earth Sciences and Environmental Engineering, Gwangju Institute of Science and Technology, \\ Gwangju, South Korea \\ ${ }^{6}$ Georgia Environmental Protection Division, Atlanta, GA, USA \\ anow at: Division of Climate \& Environmental Research, Seoul Institute of Technology, Seoul, South Korea
}

Correspondence: Hyuncheol Kim (hyun.kim@noaa.gov) and Soontae Kim (soontaekim@ajou.ac.kr)

Received: 4 August 2020 - Discussion started: 17 August 2020

Revised: 13 May 2021 - Accepted: 17 May 2021 - Published: 6 July 2021

\begin{abstract}
Sixty days after the lockdown of Hubei Province, where the coronavirus was first reported, China's true recovery from the pandemic remained an outstanding question. This study investigates how human activity changed during this period using observations of surface pollutants. By combining surface data with a three-dimensional chemistry model, the impacts of meteorological variations and variations in yearly emission control are minimized, demonstrating how pollutant levels over China changed before and after the Lunar New Year from 2017 to 2020. The results show that the reduction in $\mathrm{NO}_{2}$ concentrations, an indicator of emissions in the transportation sector, was clearly greater and longer in 2020 than in normal years and started to recover after 15 February. By contrast, $\mathrm{PM}_{2.5}$ emissions had not yet recovered by the end of March, showing a reduction of around $30 \%$ compared with normal years. $\mathrm{SO}_{2}$ emissions were not affected significantly by the pandemic. An additional model study using a top-down emission adjustment still confirms a reduction of around $25 \%$ in unknown surface $\mathrm{PM}_{2.5}$ emissions over the same period, even after realistically updating $\mathrm{SO}_{2}$ and $\mathrm{NO}_{x}$ emissions. This evidence suggests that different economic sectors in China may be recovering at different
\end{abstract}

rates, with the fastest recovery in transportation and a slower recovery likely in agriculture. The apparent difference between the recovery timelines of $\mathrm{NO}_{2}$ and $\mathrm{PM}_{2.5}$ implies that monitoring a single pollutant alone (e.g., $\mathrm{NO}_{x}$ emissions) is insufficient to draw conclusions on the overall recovery of the Chinese economy.

\section{Introduction}

Measuring pollutants can provide empirical and immediate information on human activity compared with traditional survey-based measures, although interpreting spatial and temporal trends in such data is complex. The novel coronavirus SARS-CoV-2 has struck globally since it was first reported in December 2019 in China, the first country to be affected. After strong efforts by the Chinese government, including the lockdown of Hubei Province, the outbreak seems to have eased as of the end of March 2020. New daily infections in Hubei have dropped significantly, with reported new cases dropping to zero from the thousands of new cases re- 
ported daily in February (Worldometer, 2020), and lockdown restrictions have been eased. As countries around the world struggle to slow outbreaks of the pandemic disease, it becomes important to observe and analyze signals of recovery in economic and public activity in China.

A large proportion of the surface pollutants in China originate from anthropogenic emissions by five major economic sectors: transportation, industry, power generation, residential (cooking and heating), and agriculture (Li et al., 2017). Emission changes for different economic sectors can be approximately inferred based on changes in ambient concentrations of specific pollutants if uncertainties associated with real-world emissions and meteorological variations can be reduced or accounted for. $\mathrm{NO}_{2}$ concentration is strongly associated with nitrogen oxide $\left(\mathrm{NO}_{x}=\mathrm{NO}+\mathrm{NO}_{2}\right)$ emissions (Beirle et al., 2011; Georgoulias et al., 2019), and, since mobile sources (transportation) account for a large proportion of $\mathrm{NO}_{x}$ emissions, $\mathrm{NO}_{2}$ concentrations can offer a good proxy for traffic in urban areas ( $\mathrm{Li}$ et al., 2017). Meanwhile, $\mathrm{SO}_{2}$ emissions are strongly related to the industrial and residential sectors. The agricultural sector plays a critical role in tropospheric chemistry, providing most of the ammonia emissions that contribute to the formation of inorganic aerosols (Pinder et al., 2007).

Surface observations of pollutants provide an independent data set that can be compared with socioeconomic data based on surveys. Three main components affect variations in pollutant concentrations: (1) natural variations (e.g., short-term synoptic weather, interannual meteorological variations, and long-term climate change), (2) long-term trends due to emission control, and (3) sporadic socioeconomic events (Kim et al., 2017a). The coronavirus offers a case of an emission change caused by an unprecedented, isolated social event. Therefore, signals from these first two components - meteorological variations and year-on-year emission controls must be minimized to isolate the true signal of the impact of the pandemic on air pollutant concentrations. A state-of-theart three-dimensional atmospheric chemistry model can help to separate these confounding factors. This study attempts to estimate the impact of the pandemic on Chinese regional air quality, thus inferring changes in social activity based on observations of surface pollutants.

Although early studies have reported Chinese air quality during the period in question, in terms of surface observations and air quality indices (Bao and Zhang, 2020; Chauhan and Singh, 2020; He et al., 2020; Shi and Brasseur, 2020; Xu et al., 2020), satellite observations (F. Liu et al., 2020; Q. Liu et al., 2020), atmospheric chemistry modeling (Kang et al., 2020; Li et al., 2020; Wang et al., 2020), emission estimation via inverse modeling (Miyazaki et al., 2020; Zhang et al., 2020), secondary aerosol formation (Huang et al., 2021), and human activity and energy use (Wang and $\mathrm{Su}, 2020$ ), it remains challenging to fully isolate the impact of the pandemic on the region's air quality. To quantitatively assess changes in major surface pollutants and their precursor emissions over
China during the pandemic period, we conducted a series of analyses using surface observations and atmospheric chemistry models, with simulations based on a bottom-up emission inventory and top-down assimilated emissions. Section 2 describes the observational data recorded from surface monitors and satellite, as well as the baseline modeling methodology. Section 3 describes the methodology for processing time-series data, estimating top-down emissions and assessing sectoral impacts of emissions. Section 4 presents and discusses the results. Finally, Sect. 5 summarizes the findings and their implications.

\section{Data}

\subsection{Observations}

Surface observation data were obtained from the China National Environmental Monitoring Center (CNEMC; data available at http://www.pm25.in, last access: 25 June 2021). Hourly ambient air concentration data for $\mathrm{PM}_{10}, \mathrm{PM}_{2.5}, \mathrm{CO}$, $\mathrm{NO}_{2}, \mathrm{O}_{3}$, and $\mathrm{SO}_{2}$ were available for 1571 sites (over China) and 1459 sites (within the study domain; Fig. 1). After removing sites with less than $80 \%$ data availability for each year (2017-2020, $\pm 60 \mathrm{~d}$ of Lunar New Year (LNY)), the analysis used observations from 1332 sites. Data-processing procedures are explained in Sect. 3.1 and further discussed in Sect. 4.4.

\subsection{Satellite}

The TROPOspheric Monitoring Instrument (TROPOMI) $\mathrm{NO}_{2}$ vertical column-density, level-2 data (S5P_L2_NO2) were obtained from NASA GES DISC (http://tropomi. gesdisc.eosdis.nasa.gov, last access: 25 June 2021). TROPOMI is a hyperspectral spectrometer onboard the Sentinel-5P satellite, with wavelength coverage over ultraviolet to visible (270 to $495 \mathrm{~nm}$ ), near infrared $(675-775 \mathrm{~nm})$, and shortwave infrared $(2305-2385 \mathrm{~nm})$ wavelengths (Eskes et al., 2019; van Geffen et al., 2019). High-quality pixels from level-2 data $(3.5 \mathrm{~km} \times 7 \mathrm{~km}$ resolution at the nadir) were selected using the quality flags provided by the product (qa_value $>0.75$ ) and then spatially regridded into the study domain using a conservative spatial-regridding method that preserves mass during interpolation (Kim et al., 2018, 2016, 2020).

\subsection{Model}

Meteorological and atmospheric chemistry transport models were used over East Asia with a $27 \mathrm{~km}$ horizontal resolution. The Weather Research and Forecasting Model (WRF, version 3.4.1) was used for meteorological simulations (Skamarock and Klemp, 2008). The National Oceanic and Atmospheric Administration (NOAA) National Centers for Environmental Protection (NCEP) Final Analysis (FNL) product 


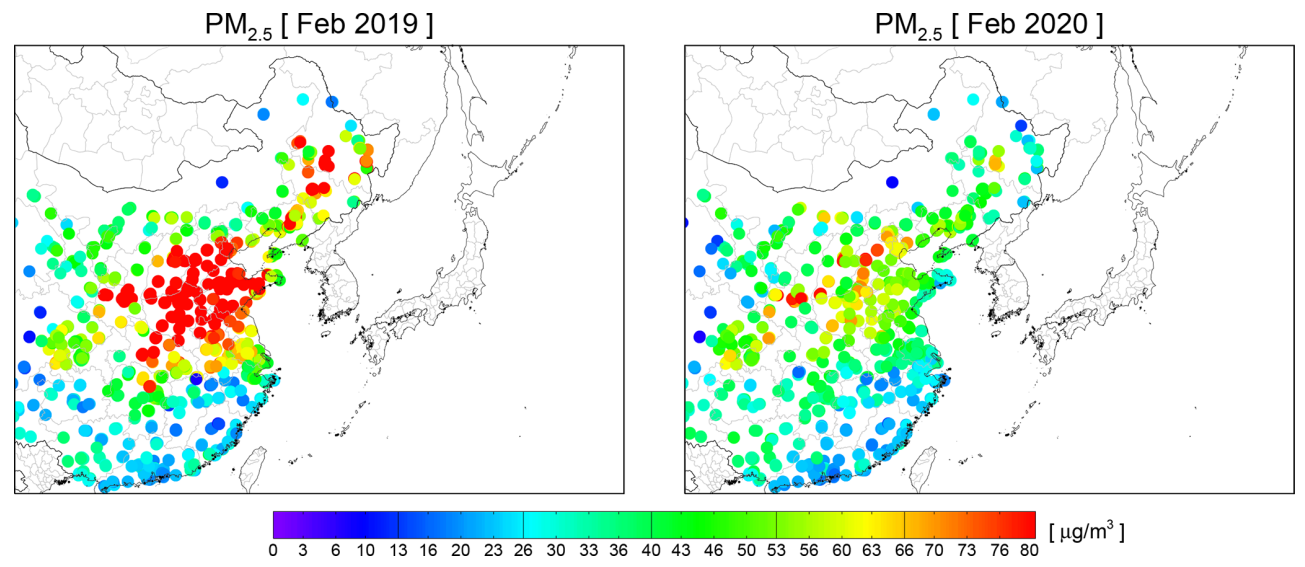

Figure 1. Geographical coverage of modeling domain and surface-monitoring sites. Monthly mean surface $\mathrm{PM}_{2.5}$ concentrations in February 2019 and February 2020 are shown.

Table 1. Physical options for meteorological and chemical simulations.

\begin{tabular}{lll}
\hline Model & Physical options & Descriptions \\
\hline WRF & Initial field & FNL (NCEP, 2000) \\
v3.4.1 & Microphysics & WSM6 (Hong et al., 2004) \\
& Cumulus scheme & Kain-Fritsch (Kain, 2004) \\
& Land surface model scheme & NOAH (Chen and Dudhia, 2001) \\
& Planetary boundary layer scheme & YSU (Hong et al., 2006) \\
\hline CMAQ & Chemical mechanism & SAPRC99 (Carter, 2003) \\
v4.7.1 & Chemical solver & EBI (Hertel et al., 1993) \\
& Aerosol module & AERO5 (Binkowski and Roselle, 2003) \\
& Advection scheme & YAMO (Yamartino, 1993) \\
& Horizontal diffusion & Multiscale (Louis, 1979) \\
& Vertical diffusion & Eddy (Louis, 1979) \\
& Cloud scheme & RADM (Chang et al., 1987) \\
\hline
\end{tabular}

(NCEP, 2000) provided the initial and boundary conditions for the WRF simulations. For chemistry simulations, CMAQ (version 4.7.1) (Byun and Schere, 2006), the MeteorologyChemistry Interface Processor (MCIP, version 3.6) (Otte and Pleim, 2010), and the Sparse Matrix Operator Kernel Emission (SMOKE) modeling framework were used, employing the meteorological inputs provided by the WRF simulations. Table 1 details the modeling configurations, and Fig. S1 in the Supplement compares models with observations. The models provide a reasonably realistic simulation of atmospheric chemical and physical processes over the considered domain, especially in terms of their daily variations from 2017 to 2019 (e.g., $R=0.91 \sim 0.94$ for $\mathrm{PM}_{2.5}$, see Emery et al. (2017) for general model performance guidance). However, in 2020, as the effects of the pandemic began to take hold, the chemical model's predictions - based on typical (as opposed to pandemic-influenced) emissions - systematically overpredicted pollutant concentrations, consistent with a pandemic-influenced reduction in emissions.

\subsection{Emission inventory}

This study used two sets of emission inventories, the Comprehensive Regional emission inventory for Atmospheric Transport Experiment (CREATE, version 2.3) (Jang et al., 2020) and the Model Inter-Comparison Study for Asia (MICS-Asia) emission inventory (MIX inventory for the year 2010) (Li et al., 2017). While the CREATE inventory is based on the latest information, including the 2016 KORUSAQ campaign (https://espo.nasa.gov/korus-aq, last access: 25 June 2021), the MIX inventory has been tested in many diverse applications (J. Li et al., 2019; K. Li et al., 2019; Zhang et al., 2017). The time-series analysis in Fig. 2 (discussed below) was based on the CREATE emission inventory, but the results of the analysis did not depend in any significant way on a choice between these two base inventories. The CREATE inventory is provided as an annual mean for each Chinese province for the year 2016 and the SMOKE preprocessor was used to convert the inventory to hourly model-ready 

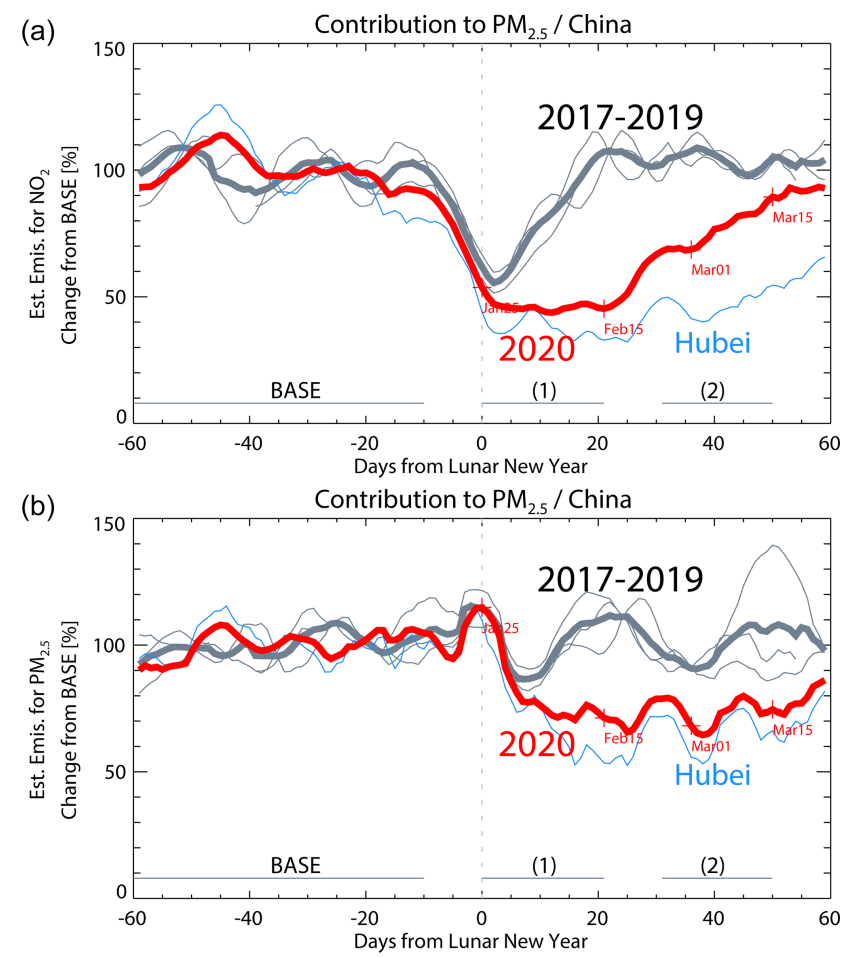

Figure 2. Time series of estimated emissions for (a) $\mathrm{NO}_{2}$ and (b) $\mathrm{PM}_{2.5}$ using 1332 surface-monitoring sites across China. The gray lines indicate 2017-2019 variations, with their average in the thick gray line, whereas the red line indicates the 2020 variation. The blue line indicates the 2020 variations in Hubei Province (46 sites). BASE is used as the pre-LNY period, and (1) and (2) denote the period of maximum impact and the recovery period, respectively.

inputs. The base model simulations use these 2016 emissions for the entire 2017-2020 modeling period.

\section{Method}

This section describes the following aspects of the analysis: (1) data-processing procedures for analyzing the time series, (2) emission adjustment procedures to update $\mathrm{SO}_{2}$ and $\mathrm{NO}_{x}$ emissions to near real time, and (3) brute-force modeling procedures to estimate Chinese emissions by sector. It should be noted that the time-series analysis (discussed in Sect. 4.1) utilizes fixed emission inventory (i.e., bottom-up emission inventory) and the emission adjustment experiment (Sect. 4.2) utilizes observation-based top-down emissions. The sectoral emission estimation method is for Sect. 4.3.

\subsection{Time-series analysis}

Four types of variation (meteorological, weekly, yearly, and the Chinese spring festival) were reduced or accounted for in the surface observations, as follows. Meteorological influences were reduced by combining surface data with output from a three-dimensional chemistry model to calculate estimated emissions. Since the model simulations with a fixed emission inventory respond to the variations in meteorological conditions, we can infer the relationship between emissions and ambient pollutant concentrations under specific weather conditions. By applying this relationship, we convert the changes in observed concentrations into the changes in emissions. Weekly variations, a unique feature of anthropogenic emissions, were removed by using a $7 \mathrm{~d}$ moving average. The impact of the Chinese spring festival, the biggest traditional holiday celebrating Lunar New Year (LNY), was normalized by rearranging the time series to center on the LNY in each solar year. The LNY alignment was necessary to account for the irregular occurrence of the LNY dates. Seven-day moving average filtering was also required to avoid unfair comparisons between different weekdays after the LNY alignment. Otherwise, we may compare different weekdays for different year (e.g., 2020 LNY on 25 January, Saturday, and 2019 LNY is February 5, Tuesday). Figure $\mathrm{S} 4$ shows that the $7 \mathrm{~d}$ moving average filter smooths but does not significantly change the time-series results. Finally, yearly emission variations were removed by setting a base period ( -60 to $-10 \mathrm{~d}$ before $\mathrm{LNY}$ ) and calculating relative changes from the average of the base period.

We followed the data-processing procedures suggested by Bae et al. (2020b) for their emissions-updating system (hereafter BAE2020). First, the observational and modeled data were paired and tested, and observation sites with more than $20 \%$ of values missing were discarded. To avoid overweighting dense urban sites, observations occurring within the same model grid cell were averaged. Second, weekly variations were removed using $7 \mathrm{~d}$ moving averages, and the impact of the Chinese spring festival was normalized by rearranging the time series to center on LNY in each year. Third, meteorological variations were removed by applying the ratio between observed and modeled concentrations. Using a simple linear assumption, observed pollutant concentrations were combined with the results of the chemical model to create estimates of actual emissions that are less sensitive to meteorological variations. Use of the linear assumption in the concentration-to-emission conversion is further discussed in Sect. 4.4 The total estimated emissions, $E_{\text {est }}$, and their relative variations, $\mathrm{rE}_{\text {est }}$, were calculated as

$$
\begin{aligned}
E_{\text {est }}(t) & =E_{\mathrm{mod}} \cdot \frac{C_{\mathrm{obs}}(t)}{C_{\mathrm{mod}}(t)}, \\
\mathrm{rE}_{\mathrm{est}}(t) & =\frac{E_{\mathrm{est}}(t)}{\sum_{t=\text { base }} E_{\mathrm{est}}(t) / n_{\text {base }}} \cdot 100 \%,
\end{aligned}
$$

where $C$ is the daily pollutant concentration; $t$ is days from LNY; base and $n_{\text {base }}$ are the pre-LNY base period (shown in Fig. 2) and its number of days, respectively; and $E_{\bmod }$ is the model emissions. To normalize the yearly changes, a base period ( -60 to $-10 \mathrm{~d}$ before LNY) was set, with relative changes calculated from the average of that base period (i.e., 


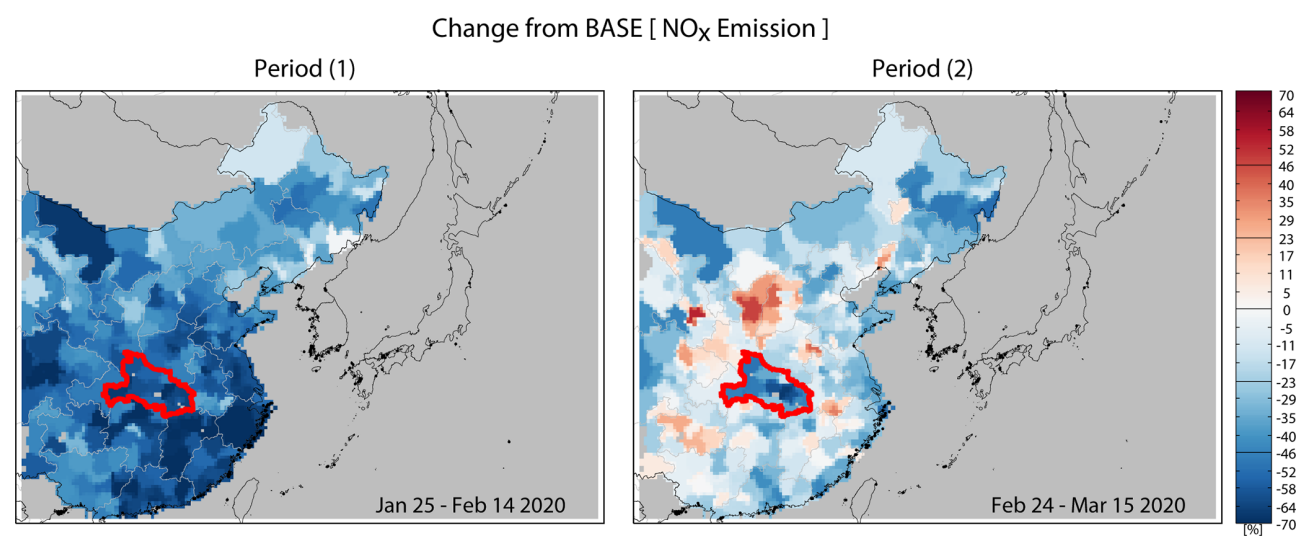

Figure 3. Spatial distribution of the change in estimated $\mathrm{NO}_{x}$ emissions from the baseline period (Fig. 2) during the period of maximum impact (25 January-14 February 2020) and the recovery period (24 February-15 March 2020). Hubei Province is marked in red.

$\left.\mathrm{rE}_{\text {est }}(t)\right)$. The impact of the pandemic was inferred by calculating the difference in estimated emissions between normal years and 2020. Since the model uses a fixed emission inventory for each year, $E_{\text {mod }}$ cancels out in the comparison.

For the spatial analyses of the data (e.g., Fig. 3), point data were converted to area format. Similar to the time-series data processing, the observational and modeled data were paired and tested. Considering the location of each paired data set, we assigned point data to their corresponding Chinese prefecture. By averaging all concentrations in each prefecture, we constructed the prefecture-level concentration data set (for each prefecture polygon), which was then converted into domain grids using a conservative spatial-regridding technique. Section 4.4 further discusses the data-processing procedures.

\subsection{Top-down emission adjustment}

For the second analysis (discussed in Sect. 4.2), we updated major pollutant emissions to a more realistic level and analyzed simulated chemical behaviors. Due to stringent emission control policies by the Chinese government, Chinese anthropogenic emissions have changed dramatically over recent years. For example, the annual mean surface $\mathrm{SO}_{2}$ concentration across China was $8.4 \mathrm{ppb}$ in 2016 but dropped to less than half of this level (3.7 ppb) in 2020. To incorporate a realistic change in emissions from 2016 to 2020, we applied observation-based emission adjustment factors to the 2016 CREATE emission inventory to reproduce emissions in 2020. In general, model emissions can be adjusted based on the ratios between observed and modeled surface concentrations:

$$
\frac{E_{\text {adj }}}{E_{\text {mod }}}=\beta \cdot \frac{C_{\mathrm{obs}}}{C_{\text {mod }}},
$$

where $\beta$ is a sensitivity factor in the emission-toconcentration conversion. $\beta$ is close to 1 if less secondary chemical reactions are involved. BAE2020 assumed a fixed $\beta=1$ to update $\mathrm{SO}_{2}$ emissions, and they demonstrated that the adjusted emissions effectively reproduced surface $\mathrm{SO}_{2}$ concentrations over China. Similar approaches were also confirmed to be effective for the $\mathrm{NO}_{x}$ emission adjustment over the same East Asian domain using satellite-based measurements of $\mathrm{NO}_{2}$ column densities (Bae et al., 2020a; Chang et al., 2016).

While this simple assumption works practically, we tried to conduct the emission adjustment processing more carefully, considering the unprecedented changes in the chemical environment during the pandemic period. We extend the approach of BAE2020, offering two major enhancements. First, we calculate daily emission adjustment factors to represent the rapid changes in emissions under the pandemic situation. We applied $14 \mathrm{~d}$ moving averages to avoid uncertainties caused by insufficient data points day to day. Second, we calculated spatial and temporal variations in $\beta$ and then applied these to the emission adjustment factors. Table 2 compares the data-processing steps used in this study with those used in BAE2020.

The $\beta$ values are calculated as follows. In the real world, the sensitivity of concentration to changes in emissions is not unique or spatially homogeneous (i.e., $\beta \neq 1$ ), especially for $\mathrm{NO}_{x}$ emissions and $\mathrm{NO}_{2}$ concentrations. $\beta$ values for specific location and time can be calculated if we have two model simulations with different emissions applied. Previous studies have calculated $\beta$ values for a model by using changes in concentration caused by a certain amount of perturbed emissions (e.g., Lamsal et al., 2011, used a $15 \%$ emission perturbation).

To obtain more realistic $\beta$ values, we have conducted two model simulations: base and adj1 runs. First, the base model simulation was conducted using a normal emission inventory, CREATE, which we have introduced previously. The second simulation, adj1 run, was conducted using perturbed emissions to estimate how the model responds according to the change in emissions. We adjusted emissions according to the 
Table 2. Comparison of data-processing steps in the emission adjustment methods used in BAE2020 and this study.

\begin{tabular}{lll}
\hline Data-processing steps & BAE2020 & This study \\
\hline $\begin{array}{l}\text { Spatial processing } \\
\text { Temporal processing }\end{array}$ & $\begin{array}{l}\text { Prefecture-level } \\
\text { Monthly }\end{array}$ & $\begin{array}{l}\text { Prefecture-level } \\
\text { Daily (14 d moving average) }\end{array}$ \\
\hline $\begin{array}{l}\text { Emission-to-concentration } \\
\text { conversion factor }(\beta)\end{array}$ & $\beta=1$ & $\begin{array}{l}\text { Varying } \\
\text { (Daily and prefecture-level) }\end{array}$ \\
\hline CMAQ simulations & $1(\operatorname{adj} 1)$ & $2(\operatorname{adj} 1 \&$ adj2) \\
Emissions adjusted & $\mathrm{SO}_{2}$ & $\mathrm{SO}_{2}, \mathrm{NO}_{x}$ \\
\hline
\end{tabular}

Note: results of "adj1" simulations were used to calculate $\beta$ values for the "adj2" simulation.

ratio between observed and modeled surface concentrations, so we can reproduce a more realistic chemical environment.

From these two simulations, the base and adj1 runs, we calculate the emissions-to-concentration sensitivity, $\beta$ values, on a specific spatial and temporal scale - for each Chinese prefecture daily. $\beta$ values are calculated as

$\beta_{p, t}=\frac{\left[E_{\mathrm{adj} 1} / E_{\mathrm{base}}\right]_{p, t}}{\left[C_{\mathrm{adj} 1} / C_{\mathrm{base}}\right]_{p, t}}$,

where $p$ and $t$ stand for indices of Chinese prefectures and specific dates. Using calculated $\beta$ values for each prefecture and date, we finally obtain the adjusted emissions for the second and final simulations: the adj2 run.

$\left[E_{\mathrm{adj} 2}\right]_{p, t}=\beta_{p, t} \cdot\left[\frac{C_{\mathrm{obs}}}{C_{\text {base }}} \cdot E_{\text {base }}\right]_{p, t}$

We further discuss the characteristics of the emissions-toconcentration sensitivity in Sect. 4.4.2.

\subsection{Estimation of sectoral contributions}

The contributions of emissions from each sector to surface $\mathrm{PM}_{2.5}$ concentrations over China were estimated using the brute-force method (BFM), an approach that uses changes in modeled outputs as a result of perturbed emission inputs (Burr and Zhang, 2011). The MIX emission inventory provides information on five sectors: residential, industry, power generation, transportation, and agriculture. Sectoral contributions were calculated by applying the perturbed emissions for each sector:

Contr.(sector) $=\frac{\left(C_{\text {base }}-C_{\Delta E, \text { sector }}\right) / \Delta E}{C_{\text {base }}} \cdot 100 \%$,

where $C$ is the surface $\mathrm{PM}_{2.5}$ concentration and $\Delta E$ is the ratio of the emission perturbations. A $50 \%$ reduction was chosen to perturb emissions for each individual sector. Fractional contributions of each emission sector were calculated compared to the sum of all five emission sector contributions. The application of the BFM to East Asian air quality models and a discussion of its uncertainties has been presented elsewhere (Kim et al., 2017b).

\section{Results}

\subsection{Time-series analysis}

Reducing meteorological, weekly, and yearly variations, as well as variations resulting from the Chinese spring festival made the comparison of pandemic-influenced surface observations to normal conditions more robust and useful. Estimated $\mathrm{NO}_{x}$ emissions (Fig. 2) display variations from the spring festival season. From 2017-2019, the estimated $\mathrm{NO}_{x}$ emissions demonstrate a clear reduction during the festival period (by up to $45 \%$ between -10 and $+20 \mathrm{~d}$ from LNY). In 2020, this reduction is slightly greater and continues for longer, implying that the coronavirus outbreak further reduced traffic in China. The difference between the estimated emissions in the 2017-2019 time series and those in the 2020 time series in Fig. 2 reflects the relative significance of the impact of the coronavirus ( $p<0.01$ for $t$ test of comparison after LNY).

Interestingly, the 2020 time series (that is, the combined effect of the spring festival and the coronavirus) remains flat from the LNY to 15 February. As both effects likely overlapped, they appear inseparable during the period. The maximum impact from the coronavirus seen in the data is a $58 \%$ reduction on 15 February 2020 from the level seen in prior, baseline years (2017-2019). The level of $\mathrm{NO}_{x}$ emissions from 1 to 15 February (close to a $50 \%$ reduction) might suggest a floor level for reduced emissions under current conditions in terms of technology and infrastructure. This might have important implications for chemical modeling and emission control, perhaps implying a floor for emission reductions that China can realistically reach under current conditions. The blue line represents a time series from Hubei only (46 sites), showing, as would be expected, that the impact in Hubei has been more significant and sustained.

The reduced $\mathrm{NO}_{x}$ emissions began to increase after 15 February, almost recovering to their normal level by the end of March 2020. Hence, the impact of the coronavirus pandemic on $\mathrm{NO}_{x}$ emissions in China lasted almost 2 months. Figure 3 shows the spatial distribution of the estimated changes in $\mathrm{NO}_{x}$ emissions from the base period to the 
period of maximum impact (25 January-14 February 2020) and the recovery period (24 February - 15 March 2020). Just after $\mathrm{LNY}, \mathrm{NO}_{x}$ emissions strongly reduce across China, but their inferred recovery is spatially inhomogeneous. As shown in Fig. 3, Hubei Province continued to show a strong reduction (by more than 50\%) compared with the pre-LNY level, even in the recovery phase (period 2). Other regions show various patterns in $\mathrm{NO}_{x}$ levels compared with previous years. These observations are consistent with space-borne, remotesensing measurements from the TROPOMI (Fig. S1). Similar to the surface observations in Fig. 3, the spatial distributions of $\mathrm{NO}_{2}$ column densities during the period of maximum impact (25 January-14 February) and the recovery period (24 February - 15 March) were generated as changes from the baseline period (26 November 2019-15 January 2020).

The impact of the virus may actually have begun before the spring festival. In normal years (2017-2019), variation in estimated pre-LNY baseline period ( -60 to $-10 \mathrm{~d}$ ) $\mathrm{NO}_{x}$ emissions is relatively small because the model uses fixed emissions and weekly variations have already been removed. However, the estimated emissions in 2020 are relatively low, starting from about $15 \mathrm{~d}$ before LNY, and this relative reduction is more pronounced in Hubei. This suggests that our baseline period in 2020 already includes a partial coronavirus impact. If this is true, the impact of the pandemic would be even stronger than inferred here, as it is based on a yearby-year comparison of concentrations during and after the typical-year base period.

Unlike the temporal trend in $\mathrm{NO}_{x}$ emissions and their spatial distribution, a comparison of changes in the $\mathrm{PM}_{2.5}$ level suggests a different story (Fig. 2b). Contrary to $\mathrm{NO}_{x}$ emissions, $\mathrm{PM}_{2.5}$ concentrations typically show a slight increase near LNY, likely due to increased $\mathrm{PM}_{2.5}$ emissions from fireworks, a long-held tradition in China (Kong et al., 2015), and show only a relatively moderate reduction from typical levels (by $10 \%-20 \%$ ) over the remainder of the spring festival. Unlike $\mathrm{NO}_{x}$ emissions, the case of $\mathrm{PM}_{2.5}$ involves both direct emissions of particulate matter and gas-to-particle conversion of emitted precursors (e.g., $\mathrm{SO}_{2}, \mathrm{NO}_{x}, \mathrm{NH}_{3}$, VOCs volatile organic compounds) mediated by atmospheric chemical transformations. As discussed in the Method section, we assume the same approximate relationship for $\mathrm{PM}_{2.5}$ as with $\mathrm{NO}_{x}$ between the ambient observations and their associated emissions. This approach suggests that emissions decreased by roughly $30 \%$ from normal levels through the end of March to reach $72.7 \pm 6.6 \%$ of the 2017-2019 level from 4 February to 25 March 2020. Interestingly, the pandemic does not seem to have significantly affected $\mathrm{SO}_{2}$ emissions (see Fig. S3), suggesting that the pandemic's effects on the power generation and industrial sectors have been relatively small.

\subsection{Experiment with updated $\mathrm{SO}_{2}$ and $\mathrm{NO}_{x}$ emissions}

As discussed in Sect. 3.2 above, we used an alternative approach to investigate unidentified $\mathrm{PM}_{2.5}$ emissions, specifically applying more realistic $\mathrm{SO}_{2}$ and $\mathrm{NO}_{x}$ emission adjustments. Using this methodology, we repeated CMAQ simulations with $\mathrm{SO}_{2}$ and $\mathrm{NO}_{x}$ emissions adjusted based on surface measurements. Daily and prefecture-level emissionadjustment factors were calculated and applied to the baseline emission inventory. The two CMAQ simulations - a baseline simulation with the CREATE emission inventory and an adjustment simulation with updated emissions - were both compared with observations from surface-monitoring sites (Fig. 4). Individual site comparisons are also available in Fig. S11.

For both $\mathrm{SO}_{2}$ and $\mathrm{NO}_{2}$ concentrations, the CMAQ simulation with adjusted emissions performed well, reproducing observed variations in surface concentrations. It should be noted that the CREATE v2.3 emission inventory we used was constructed for 2016 and applied to a 2020 simulation. Before $\mathrm{LNY}$, simulated $\mathrm{NO}_{2}$ concentrations with both the baseline and adjusted emission inventory agreed well with observations, implying that there were no significant changes in the $\mathrm{NO}_{x}$ emission level between 2016 and 2020. Near LNY, the baseline $\mathrm{NO}_{2}$ simulations differ significantly from observations, while the simulation with adjusted emissions successfully reproduced the huge reductions in the LNY and pandemic period. The difference between the baseline and adjusted simulations almost disappears at the end of March, consistent with the result of the time-series analysis (Fig. 2). On the other hand, the baseline $\mathrm{SO}_{2}$ simulations greatly overestimate observations by 2 or 3 times, implying that nominal, real-world $\mathrm{SO}_{2}$ emissions in 2020 are much smaller than those reflected in the 2016 emission inventory. By applying the top-down adjustment described here, simulations could successfully reproduce surface $\mathrm{SO}_{2}$ concentrations, reducing RMSE by $93 \%$ from 9.19 to $0.62 \mathrm{ppb}$. The updated $\mathrm{SO}_{2}$ and $\mathrm{NO}_{x}$ emission inventories appear to successfully reproduce variations in surface $\mathrm{PM}_{2.5}$ concentrations, even after the start of LNY celebrations. However, in early February, as the impact of the COVID-19 pandemic became more significant, the baseline run (with the CREATE emission inventory) does not simulate a sudden drop in $\mathrm{PM}_{2.5}$ observations, while the adjusted emissions run does so.

A closer look, however, reveals that the real trend in $\mathrm{PM}_{2.5}$ emissions cannot be explained by the change in two major inorganic aerosol precursors: $\mathrm{SO}_{2}$ and $\mathrm{NO}_{x}$. Figure 5 depicts the time series of normalized mean biases (NMBs) of surface $\mathrm{PM}_{2.5}$ concentrations. Before LNY, $\mathrm{PM}_{2.5} \mathrm{NMB}$ is mostly negative, showing the adjusted emission simulation slightly underestimates particulate matter. After LNY, $\mathrm{PM}_{2.5} \mathrm{NMB}$ changes prominently, showing the simulation clearly overestimates observations by about $20 \% \mathrm{NMB}$ in $\mathrm{PM}_{2.5}$ concentration. Before and after $\mathrm{LNY}, \mathrm{PM}_{2.5} \mathrm{NMB}$ moves by $25.1 \%$, from $-4.1 \%$ to $21.0 \%$, implying that the model suddenly 

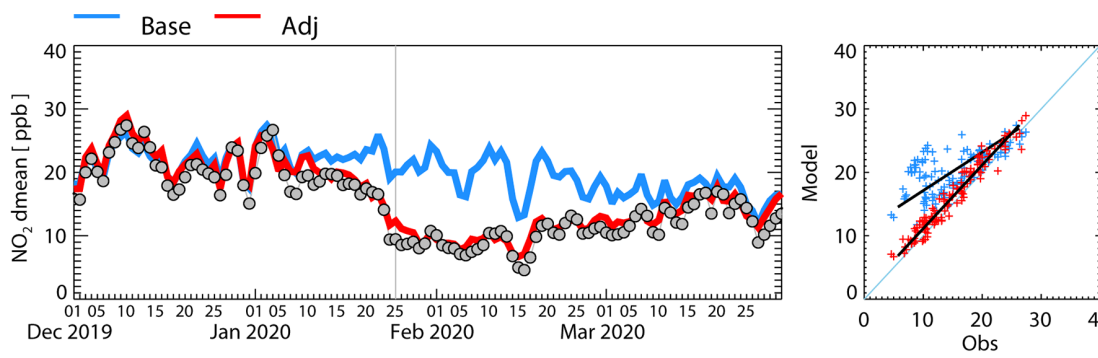

mean_x $=15.04$

mean_y $=20.16$

Bias $=5.13$

RMSE $=6.60$

$Y=0.60 X+11.09$

$R=0.65$

mean_x $=15.04$

mean_y $=16.18$

Bias $=1.14$

RMSE $=1.68$

$Y=1.00 X+1.11$
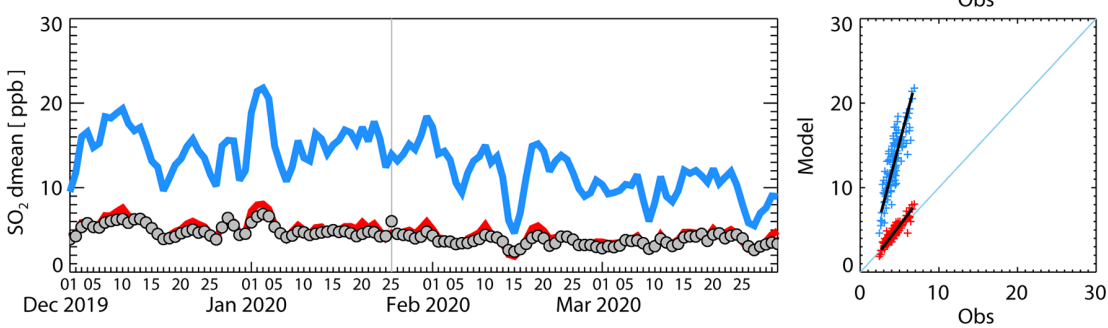

mean_x $=4.31$

mean_x $=4.31$
mean_y $=12.92$

Bias $=8.61$

RMSE $=9.0$

$Y=3.54 X+-2.33$

$\mathrm{R}=0.85$

mean $x=4.3$

mean_x $=4.31$
mean_y $=4.70$

Bias $=0.39$

Bias $=0.39$
RMSE $=0.61$

$Y=1.22 X+-0.57$
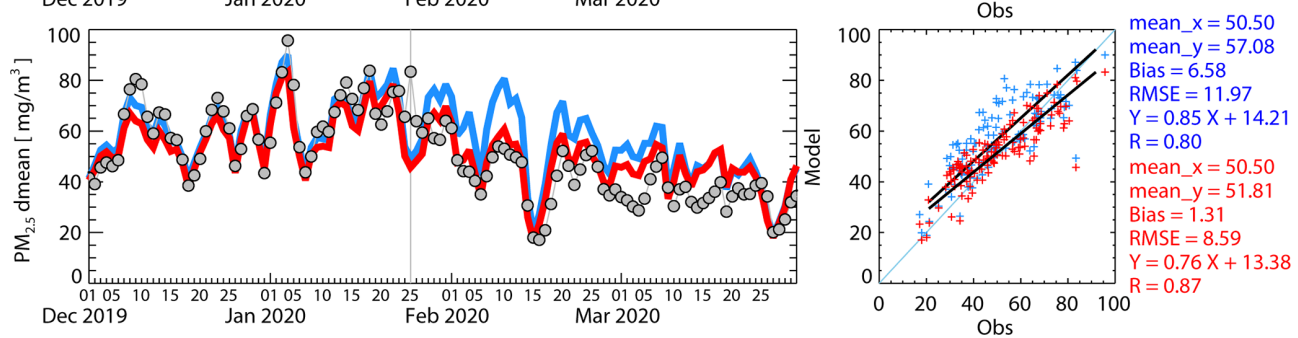

Figure 4. Time series and scatterplots of observed and modeled surface concentrations of $\mathrm{SO}_{2}, \mathrm{NO}_{2}$, and $\mathrm{PM}_{2.5}$ from 1332 Chinese surfacemonitoring sites during the pandemic period. Model simulations using the baseline emission inventory (CREATE) and top-down adjusted emissions are shown in blue and red, respectively. Observations are represented by gray circles.

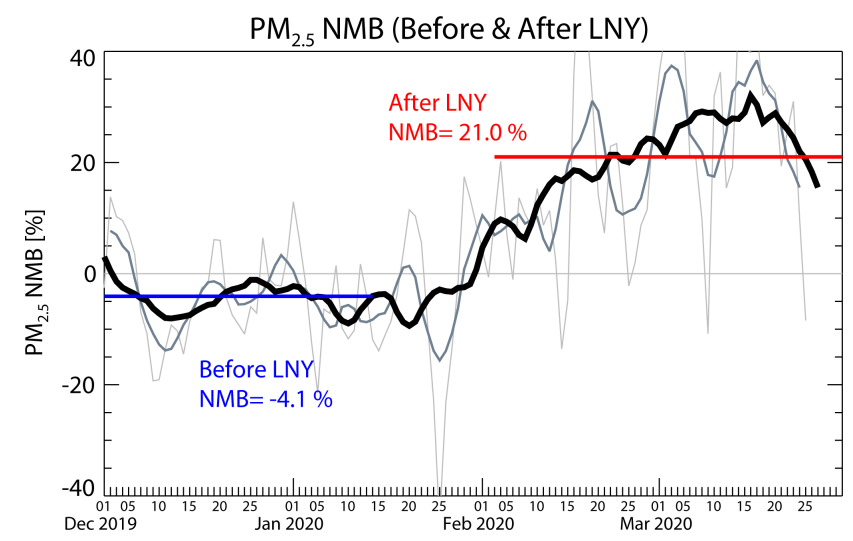

Figure 5. Time series of surface $\mathrm{PM}_{2.5}$ normalized mean bias during the pandemic period between observed and modeled data with adjusted emissions (i.e., $\mathrm{SO}_{2}$ and $\mathrm{NO}_{x}$ emissions adjusted). Mean NMBs before and after LNY are also marked. Raw, $7 \mathrm{~d}$, and $14 \mathrm{~d}$ moving average NMBs are shown in thin, medium-thin, and thick lines, respectively. overestimates $\mathrm{PM}_{2.5}$ concentrations by $25 \%$ after LNY. In other words, unknown, non-modeled emissions (that is, non$\mathrm{SO}_{2}$ and non- $\mathrm{NO}_{x}$ emissions) are clearly reduced enough during the pandemic period (February and March) to account for $25 \%$ of total $\mathrm{PM}_{2.5}$ concentration at baseline. This result is consistent with findings (Sect. 4.1) that changes in $\mathrm{SO}_{2}$ and $\mathrm{NO}_{x}$ emissions alone cannot explain the reduced $\mathrm{PM}_{2.5}$ concentrations in March.

\subsection{Sectoral contributions to emissions}

One remaining question is why the recovery of $\mathrm{NO}_{x}$ emissions and unchanged $\mathrm{SO}_{2}$ emissions at the end of March did not lead to the recovery of $\mathrm{PM}_{2.5}$, which might be explained by considering the time-varying emission contribution of each economic sector. Sensitivity tests using the CMAQ model reveal that the residential and agricultural sectors are most dominant in the early months of the year (Fig. 6), accounting for more than $60 \%$ of surface $\mathrm{PM}_{2.5}$ concentration over China. As emissions in the residential sector are primarily from cooking and heating with anthracite coal and wood, emissions which continue even during a pandemic, one possible explanation is that emissions from the agricultural sector reduced as a result of pandemic-related delays in planting and fertilizing. 


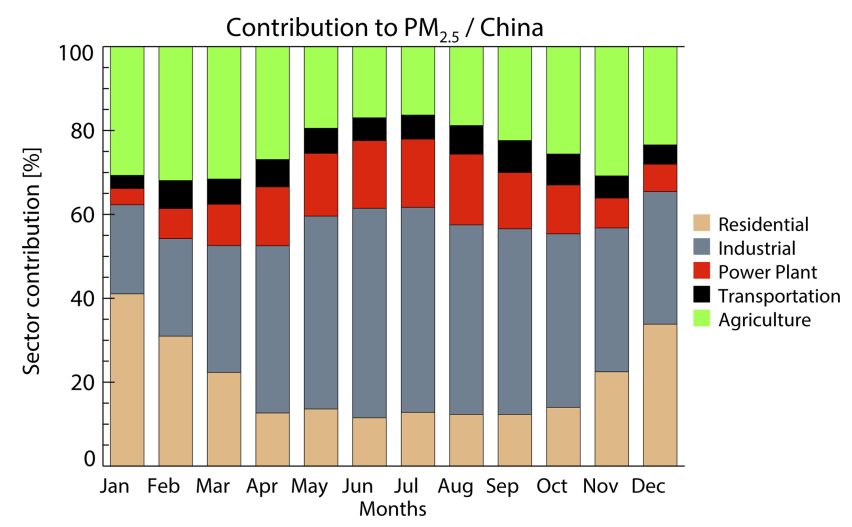

Figure 6. Monthly variations in emission contributions to surface $\mathrm{PM}_{2.5}$ concentrations over China by sector. The contributions from the five sectors (residential, industry, power generation, transportation, and agriculture) were estimated using a brute-force perturbation method.

February is the start of the spring-crop planting period in southern China. The coronavirus outbreak could have impacted both field crops and livestock farms. Inputs, such as fertilizer and animal feed, have reportedly been scarce as a result of transportation disruptions, and seasonal workers have reportedly been lacking due to quarantine controls or fears (Quanying, 2020; Yu, 2020; Zhang and Xiong, 2020). Agricultural activities that generate particulate matter, such as biomass burning to clear debris and the generation of airborne dust during tilling, are reduced in intensity during the pandemic. Reduced $\mathrm{NH}_{3}$ emissions as a result of diminished livestock farming activities might also be a factor leading to lower $\mathrm{PM}_{2.5}$ concentrations.

\subsection{Further discussions on the methods}

\subsubsection{On the data processing of time-series analysis}

We further discuss data-processing procedures here. Figure 7 presents a time series of surface pollutants proceeding through data-processing steps. Even in raw format, $\mathrm{NO}_{2}$ exhibits clear impacts from the pandemic. Impacts on other pollutants (CO, $\mathrm{PM}_{10}$, and $\left.\mathrm{PM}_{2.5}\right)$, however, are not easily recognizable until confounding signals are fully removed. Interpreting $\mathrm{SO}_{2}$ concentration data is particularly illuminating. While $2020 \mathrm{SO}_{2}$ concentrations are substantially lower than those of previous years, the time series obtained after the data processing described here suggests that $\mathrm{SO}_{2}$ emissions are mostly consistent before and after LNY. That is, lower $\mathrm{SO}_{2}$ concentrations in 2020 seem to be a continuation of year-over-year reductions and not a result of the pandemic.

Note that the various instances of linear assumptions used in this analysis should be interpreted with caution especially considering its spatiotemporal resolution and chemical characteristics. Variations in emissions and in chemical and physical processes, including chemical reactions, transport, and dispersion, can create large gradients on local scales that are likely poorly represented in the WRF and CMAQ modeling performed here, even as their importance is somewhat smoothed over regional and nationwide scales. Observed concentrations of a pollutant are generally proportional to the emissions associated with that pollutant; conceptually, a simple linear relationship between emissions and pollutants is assumed. For the pollutants $\mathrm{NO}_{2}$ and $\mathrm{SO}_{2}$, these are $\mathrm{NO}_{x}$ and $\mathrm{SO}_{2}$ emissions, respectively. BAE2020 demonstrated that this concentration-to-emission conversion method can be used effectively at the Chinese prefecture level. Discussion of the spatial representativeness of Chinese surface-monitoring data and associated uncertainties is also presented in BAE2020. For inferring $\mathrm{PM}_{2.5}$-related emissions, the analysis is more complicated because $\mathrm{PM}_{2.5}$ results from both primary and secondary (precursor) emissions. While the pollutant-emissions relation for $\mathrm{PM}_{2.5}$ is nonlinear, especially over relatively small spatial and temporal scales, it is still approximately valid over larger geographical regions and longer time periods.

The validity of the linear assumption was tested through a model sensitivity analysis. A CMAQ simulation with $50 \%$ reduced emissions yielded an approximately $50 \%$ reduction in surface $\mathrm{PM}_{2.5}$ concentrations over most regions in China (Table S1 in the Supplement). Taken as a whole, surface $\mathrm{PM}_{2.5}$ concentrations are roughly proportional to overall emissions. Thus, the simplifying assumption of linearity appears reasonable for the more complex $\mathrm{PM}_{2.5}$ case, generating a time series of estimated pollutant emissions without meteorological variations. Nevertheless, $\mathrm{PM}_{2.5}$ emissions estimated with this analysis are necessarily more uncertain than are $\mathrm{NO}_{x}$ emissions. Notably, Table $\mathrm{S} 1$ also shows that CMAQ simulations with adjustments in $\mathrm{SO}_{2}, \mathrm{NO}_{x}$, and $\mathrm{NH}_{3}$ individually showed disproportionately lower responses, suggesting that surface $\mathrm{PM}_{2.5}$ concentrations are influenced by other emissions (e.g., elemental carbon and organic carbon emissions) and/or nonlinear processes that likely vary with atmospheric chemistry regime.

\subsubsection{On the emission adjustment experiment}

As stated in the methodology section, we further discuss here the emissions-to-concentration sensitivities (i.e., $\beta$ ). The $\beta$ values can be calculated using any two model simulations based on different emission inputs, by comparing the change in emissions with the change in simulated concentrations. Furthermore, if we specifically change the emissions according to the ratio of observations and the base model simulation, we further simplify the emission scaling factor as follows.

For this simulation, adj1, if we apply the adjusted emissions using the ratio of the observed and modeled concentrations, the adjusted emissions for the adj1 run, $E_{\text {adj } 1}$, are

$E_{\mathrm{adj} 1}=\frac{C_{\mathrm{obs}}}{C_{\mathrm{base}}} \cdot E_{\mathrm{base}}$. 


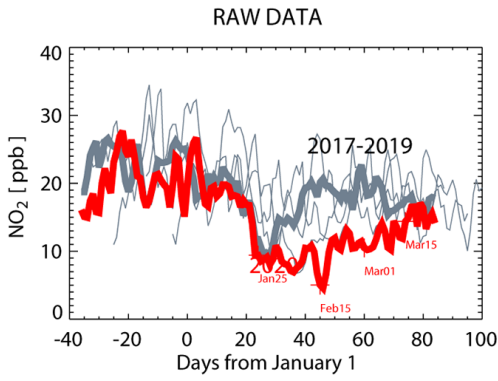

\section{DATA PROCESSING PROCEDURES}
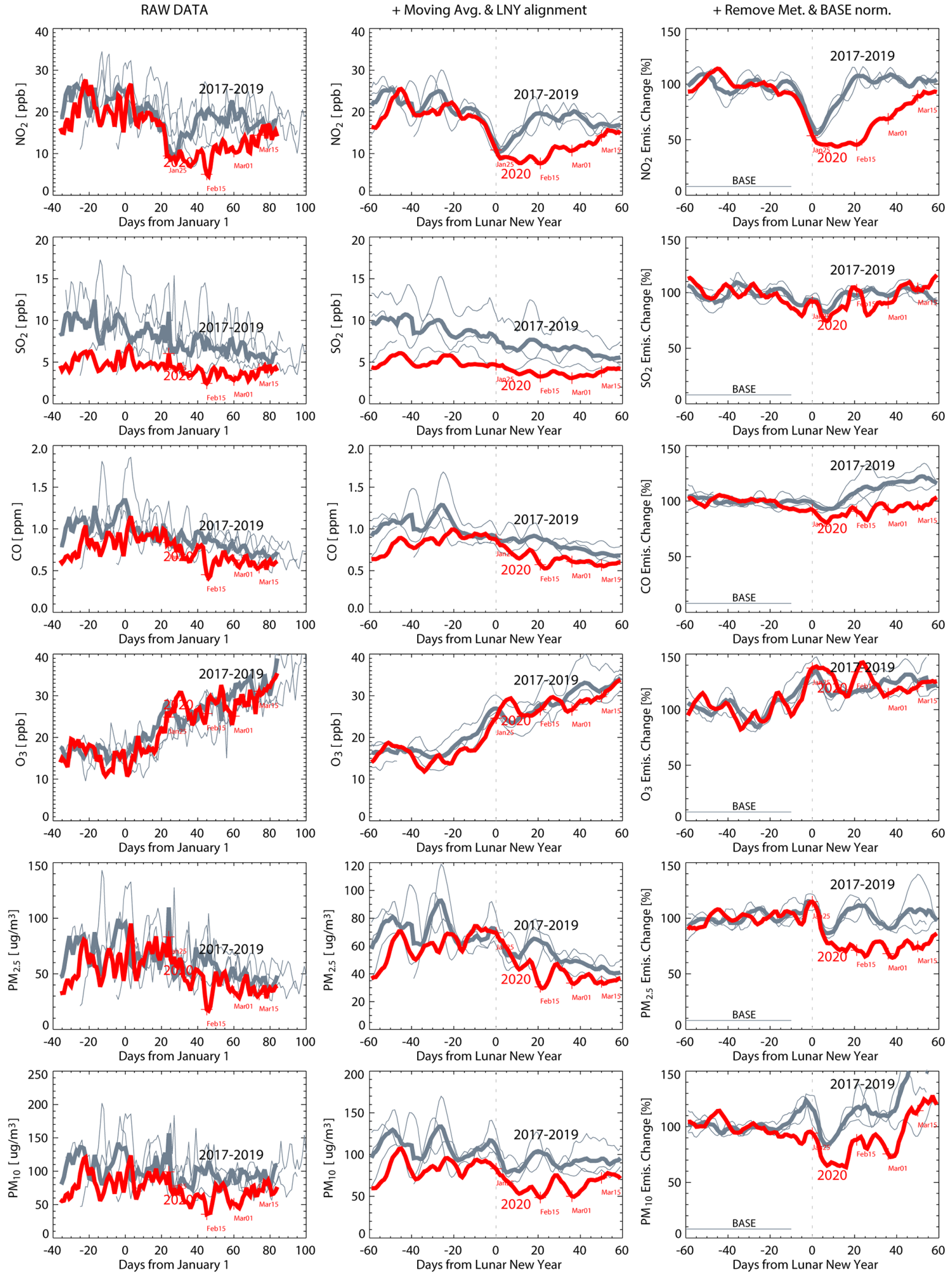

Figure 7. Time series of surface $\mathrm{NO}_{2}, \mathrm{SO}_{2}, \mathrm{CO}, \mathrm{O}_{3}, \mathrm{PM}_{2.5}$, and $\mathrm{PM}_{10}$ concentrations over China following the data-processing procedures step by step. Raw data (left column), data after applying a $7 \mathrm{~d}$ moving average and an LNY alignment (middle column), and data after removing meteorological variations and calculating variations from the baseline periods (right column) are all shown. 
If we apply this to Eq. (4), we can obtain

$\beta=\frac{E_{\mathrm{adj} 1} / E_{\mathrm{base}}}{C_{\mathrm{adj} 1} / C_{\mathrm{base}}}=\frac{C_{\mathrm{obs}} / C_{\mathrm{base}}}{C_{\mathrm{adj} 1} / C_{\mathrm{base}}}=\frac{C_{\mathrm{obs}}}{C_{\mathrm{adj} 1}}$.

Therefore, the emission adjustment factors in the next simulation (adj2) can be found using Eq. (5):

$E_{\mathrm{adj} 2}=\beta \cdot \frac{C_{\mathrm{obs}}}{C_{\mathrm{base}}} \cdot E_{\mathrm{base}}=\left[\frac{C_{\mathrm{obs}}}{C_{\mathrm{adj} 1}} \cdot \frac{C_{\mathrm{obs}}}{C_{\mathrm{base}}}\right] \cdot E_{\mathrm{base}}$,

where adj2 indicates the second and final simulation for the top-down emission adjustment method.

From here, the $\left[\frac{C_{\mathrm{obs}}}{C_{\mathrm{adj} 1}}\right]$ term, or $\beta$, can be interpreted as an additional adjustment factor to the original adjustment factor in adj1, $\left[\frac{C_{\text {obs }}}{C_{\text {base }}}\right]$. If the emission modification in adj 1 results in the same percentage change in concentrations, $C_{\mathrm{obs}} / C_{\mathrm{adj} 1}=$ 1 , we do not need the secondary adjustment. If the simulated concentration from adj1 is smaller (larger) than the observations, we need to increase (reduce) the amounts of emissions. This procedure was applied to create new 2020 emissions of both $\mathrm{SO}_{2}$ and $\mathrm{NO}_{x}$.

In most cases, the calculated $\beta$ values are close to 1 (Fig. S5), implying that the simple assumption $\beta=1$ in BAE2020 remains effective. The $\beta$ values for $\mathrm{NO}_{x}$ emissions are slightly higher than those for $\mathrm{SO}_{2}$ emissions over polluted areas (Fig. S6), which implies that more secondary reactions are involved in tropospheric $\mathrm{NO}_{x}$ chemistry.

Both enhancements to the top-down simulations $-\beta$ values and the daily application of emission adjustment factors clearly improved the model's performance, especially in the pre-LNY periods. While the monthly emission adjustments failed to represent the rapid changes in $\mathrm{NO}_{2}$ concentrations after 25 January 2020 (Fig. S7), the daily adjustment method successfully modeled these changes (Fig. 4). The general underestimation of $\mathrm{NO}_{2}$ concentrations was corrected using the $\beta$ values (Fig. 4). The improved model performance was confirmed by comparing the spatial distributions and scatterplots before and after these adjustments (Figs. S8-S10). Spatial distributions of RMSEs of model performances in $\mathrm{SO}_{2}, \mathrm{NO}_{2}$, and $\mathrm{PM}_{2.5}$ are also summarized in Fig. S12.

Understanding the characteristics of the $\beta$ values in terms of their spatial distribution, temporal variation, and chemical difference is important for several reasons. In the emission update procedure in practice, we can apply the pre-calculated $\beta$ values from the look-up table if the $\beta$ values show general consistency according to their location, time, and chemical component. For the emission control policy, the $\beta$ values provide valuable information on the efficiency of emission control because they suggest how effectively pollutant concentrations can be removed given the amount of emission control by the government.
Figure 8 summarizes the characteristics of the $\beta$ values. As they are defined as the ratio of the emission change (i.e., $E_{\text {adj1 }} / E_{\text {base }}$ ) to the change in concentrations (i.e., $C_{\text {adj1 } 1} / C_{\text {base }}$ ), the slopes of the fitted lines in the scatterplots describe the emissions-to-concentration sensitivities for $\mathrm{SO}_{2}$ and $\mathrm{NO}_{2}$ (Fig. 8a and b). The histogram of the occurrence of the $\beta$ values also confirms that for both $\mathrm{SO}_{2}$ and $\mathrm{NO}_{2}$, the calculated $\beta$ values are centered slightly over 1 $\left(\right.$ mean $=1.42$ and median $=1.27$ for $\mathrm{SO}_{2}$ and mean $=1.40$ and median $=1.26$ for $\mathrm{NO}_{2}$ ) (Fig. S13). Figure $8 \mathrm{c}$ and $\mathrm{d}$ demonstrate the spatial distributions of the $\beta$ values over Chinese territories. Except for a few outside locations, the $\beta$ values are mostly consistent, around 1 . We further investigated the temporal variations in the $\beta$ values by showing the daily variations in the estimated $\beta$ values for selected Chinese provinces (Fig. 8e and f). It is evident that the $\beta$ values differ by location, implying that the emissions-to-concentration sensitivities vary for different regions likely due to their unique chemical and emission environment. However, for each location, the $\beta$ values are mostly consistent over time. For the practical use of the $\beta$ values in the emission update procedure, we may use region-specific sensitivity parameterization since their temporal variations over a specific region are not significant.

To evaluate the emission update approach, the key feature in this study is the validation of $\mathrm{PM}_{2.5}$ concentration. We used observation-based $\mathrm{SO}_{2}$ and $\mathrm{NO}_{2}$ emission adjustments, and there was no adjustment in the primary $\mathrm{PM}_{2.5}$ emissions, meaning that the improvement of $\mathrm{PM}_{2.5}$ is achieved through chemical reactions and their balances. The surface concentrations of surface $\mathrm{PM}_{2.5}$ concentrations, especially inorganic aerosols, are formed by secondary reactions, which are determined by the balance of chemical reactions for nitrate, sulfate, and ammonium. The performance of the $\mathrm{PM}_{2.5}$ simulations provides strong evidence that the top-down emission adjustment method used in this study is valid and successfully reproduces a realistic chemical environment.

Formation efficiency of sulfate aerosols by updating $\mathrm{SO}_{2}$ and $\mathrm{NO}_{x}$ emission is also very interesting. From Fig. 4, one may notice that the change in total $\mathrm{PM}_{2.5}$ concentration is not prominent in the pre-pandemic period, even with strong reduction in $\mathrm{SO}_{2}$ emissions. Modeled PM speciation components show that the reduced sulfate concentrations were canceled out by the increased nitrate concentrations, due to the balance of nonlinear nitrate-sulfate-ammonium chemistry. Nitrate is the most dominant component of $\mathrm{PM}_{2.5}$ during the wintertime (contributing $\sim 50 \%$ while sulfate contributes $14 \%$ ), and the sudden drop of $\mathrm{PM}_{2.5}$ concentrations during the pandemic is mostly driven by the change in nitrate concentrations. This result implies an important message to emission control policy, suggesting that both $\mathrm{SO}_{2}$ and $\mathrm{NO}_{x}$ emission reductions will be required to achieve better emission reduction efficiency. 
(a)

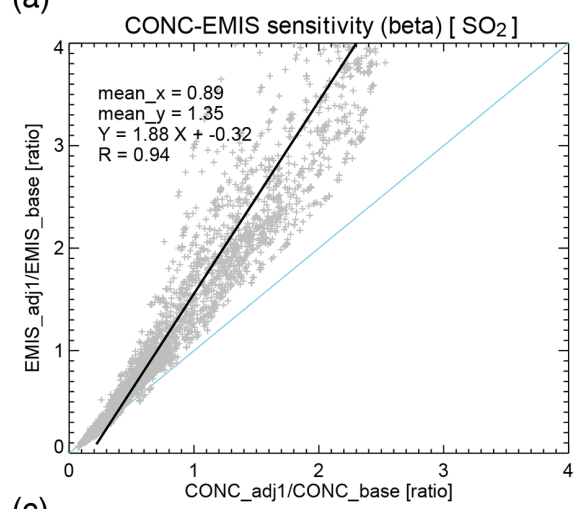

(c)

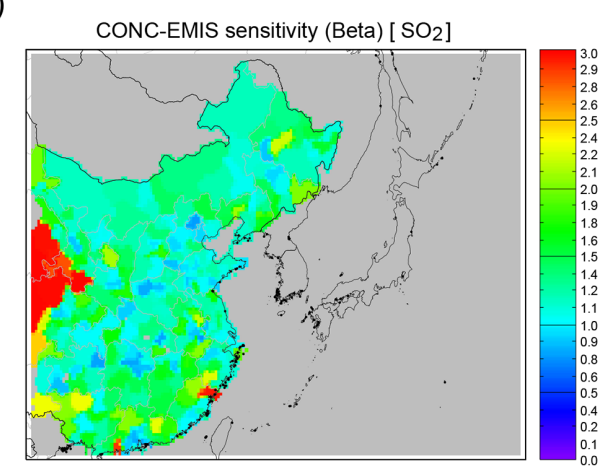

(e)

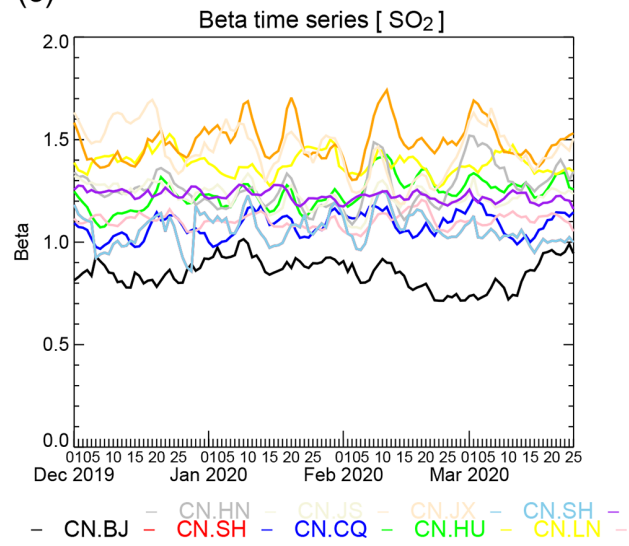

(b)

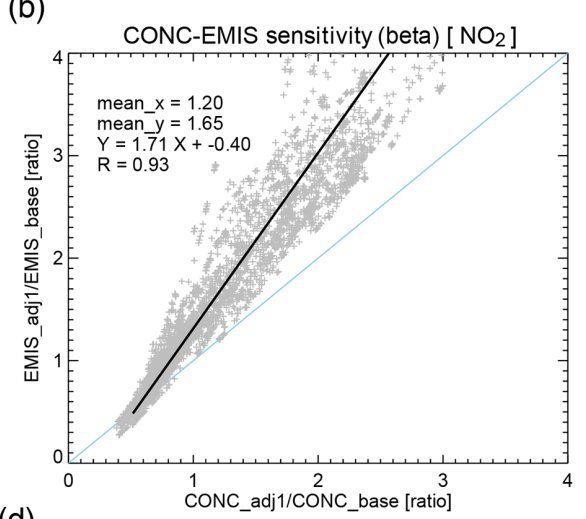

(d)

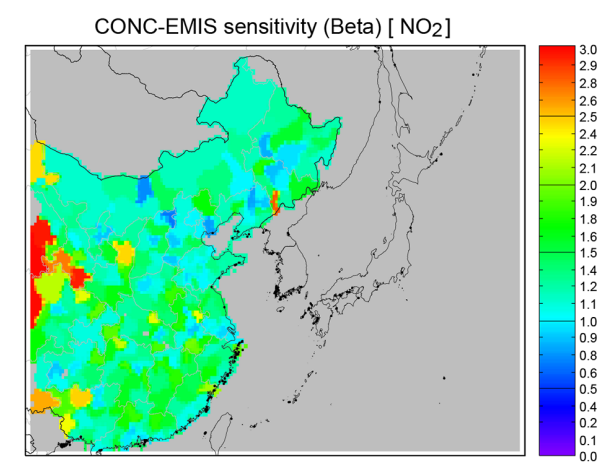

(f)

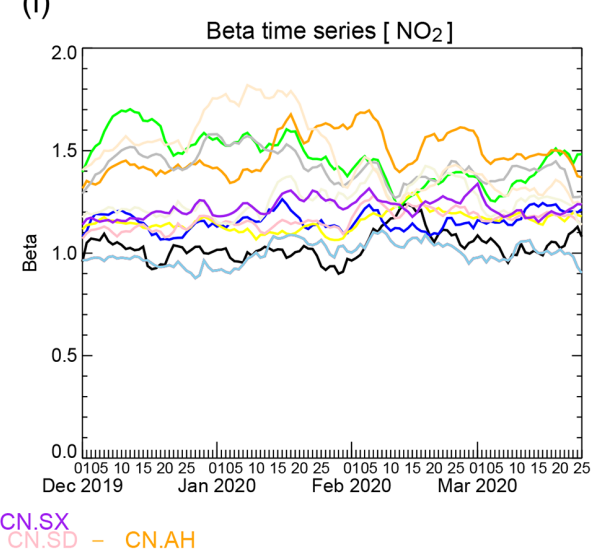

Figure 8. Calculation of the concentration-to-emissions sensitivities $(\beta)$ for the emission adjustment experiment of $\mathrm{SO}_{2}$ (left column) and $\mathrm{NO}_{2}$ (right column). The $\beta$ values are obtained as the ratio of the emission change (i.e., Emis_adj/Emis_base) to the change in concentrations (i.e., Conc_adj1/Conc_base), which is also consistent with the slope in the scatterplot (a, b). Spatial variations in the average concentrationto-emissions sensitivities $(\beta)$ during January to March 2020 over China (c, d). The temporal variations in the $\beta$ values for selected Chinese provinces are shown in the lower panel (e,f). (BJ: Beijing; SH: Shanghai; CQ: Chongqing; HU: Hubei; SD: Shandong; AH: Anhui; HN: Hunan; JS: Jiangsu; SX: Shanxi).

\section{Summary}

We investigated changes in observed surface pollutant concentrations and precursor emissions over China and inferred changes in human activity as a result of the coronavirus pandemic. Three analyses were conducted: (1) a time-series analysis, (2) an emission adjustment experiment, and (3) sectoral emission contribution estimations. First, we removed four types of variation (meteorological, weekly, yearly, and the LNY) to isolate impacts of coronavirus pandemic from observed surface pollutant concentrations. A chemistry model simulation with fixed emission inventory was used to remove meteorological variations. The analysis has shown that $\mathrm{NO}_{x}$ emissions across China recovered to almost normal levels 2 months after LNY. However, considering the estimated changes in emissions associated with 
$\mathrm{PM}_{2.5}$, some emissions remain missing, as of the end of March 2020, compared with normal years. Second, an alternative modeling approach using updated real-time $\mathrm{SO}_{2}$ and $\mathrm{NO}_{x}$ emissions also suggested that about $25 \%$ of $\mathrm{PM}_{2.5}$ emissions are likely missing from the period. Third, impacts of sectoral emissions were presented to infer the role potential missing emissions or activities.

The surface observations of pollutants and inferred precursor emissions across China suggest that the country is recovering, as evidenced by the apparent resumption of nearnormal transportation-related emissions. The pandemic appears not to have strongly affected the industrial sector; continued depression in estimated $\mathrm{PM}_{2.5}$-associated emissions may be due to effects on the agricultural sector. If the sustained reduction in $\mathrm{PM}_{2.5}$ is due to reduced activity in the agricultural sector, agricultural production could be affected, at least in the short term. This could hold important implications for China's path to recovery and, potentially, for broader parts of the world if similar types of agricultural impacts occur elsewhere.

The data analysis approach used here has attempted to isolate the ambient data signal due to the coronavirus from other sources of variation. The apparent difference between the recovery timelines for $\mathrm{NO}_{2}$ and $\mathrm{PM}_{2.5}$ suggests that estimating $\mathrm{NO}_{x}$ emissions alone is insufficient to draw conclusions about the overall recovery of the Chinese economy. Overall, changes in concentrations of atmospheric pollutants can provide useful information about the spatial and temporal economic impacts of the coronavirus pandemic, a serious global issue.

Code availability. WRF and CMAQ codes are available at https: //www2.mmm.ucar.edu/wrf/users/download/get_sources.html (last access: 25 June 2021) (WRF, 2021) and https://github.com/USEPA/ CMAQ/tree/4.7.1 (last access: 25 June 2021) (Github, 2021), respectively.

Data availability. CNEMC data are available at http://www.pm25. in (last access: 25 June 2021) (CNEMC, 2021). TROPOMI data are available at http://tropomi.gesdisc.eosdis.nasa.gov (last access: 25 June 2021) (NASA GES DISC, 2021).

Supplement. The supplement related to this article is available online at: https://doi.org/10.5194/acp-21-10065-2021-supplement.

Author contributions. HCK and SK conceived the study. HCK and MC prepared the paper. SK, CB, MB, and EK conducted the model simulation. Critical review, commentary, and editing of the written work were done by DL, RS, BUK, JHY, and AS. All authors gave approval to the final version of the paper.
Competing interests. The authors declare that they have no conflict of interest.

Disclaimer. The scientific results and conclusions, as well as any views or opinions expressed herein, are those of the author(s) and do not necessarily reflect the views of NOAA or the Department of Commerce.

Financial support. This research was supported by the National Air Emission Inventory and Research Center (NAIR), South Korea. Dasom Lee and Jin-Ho Yoon were supported by the National Research Foundation of Korea under the grant NRF2021R1A2C1011827.

Review statement. This paper was edited by James Allan and reviewed by five anonymous referees.

\section{References}

Bae, C., Kim, H. C., Kim, B.-U., and Kim, S.: Surface ozone response to satellite-constrained $\mathrm{SO}_{2}$ emission adjustments and its implications, Environ. Pollut., 258, 113469, https://doi.org/10.1016/j.envpol.2019.113469, 2020a.

Bae, C., Kim, H. C., Kim, B.-U., Kim, Y., Woo, J.-H., and Kim, S.: Updating Chinese $\mathrm{SO}_{2}$ emissions with surface observations for regional air-quality modeling over East Asia, Atmos. Environ., 228, 117416, https://doi.org/10.1016/j.atmosenv.2020.117416, 2020b.

Bao, R. and Zhang, A.: Does lockdown reduce air pollution? Evidence from 44 cities in northern China, Sci. Total Environ., 731, 139052, https://doi.org/10.1016/j.scitotenv.2020.139052, 2020.

Beirle, S., Boersma, K. F., Platt, U., Lawrence, M. G., and Wagner, T.: Megacity Emissions and Lifetimes of Nitrogen Oxides Probed from Space, Science, 333, 1737-1739, https://doi.org/10.1126/science.1207824, 2011.

Binkowski, F. S. and Roselle, S. J.: Models-3 Community Multiscale Air Quality (CMAQ) model aerosol component 1. Model description, J. Geophys. Res., 108, 2001JD001409, https://doi.org/10.1029/2001JD001409, 2003.

Burr, M. J. and Zhang, Y.: Source apportionment of fine particulate matter over the Eastern U. S. Part I: source sensitivity simulations using CMAQ with the Brute Force method, Atmos. Pollut. Res., 2, 300-317, https://doi.org/10.5094/APR.2011.036, 2011.

Byun, D. and Schere, K. L.: Review of the Governing Equations, Computational Algorithms, and Other Components of the Models-3 Community Multiscale Air Quality (CMAQ) Modeling System, Appl. Mech. Rev., 59, 51-77, https://doi.org/10.1115/1.2128636, 2006.

Carter, W. P. L.: The SAPRC-99 Chemical Mechanism and Updated VOC Reactivity Scales, available at: http://www.cert.ucr. edu/ carter/reactdat.htm (last access: 25 June 2021), 2003.

Chang, C.-Y., Faust, E., Hou, X., Lee, P., Kim, H. C., Hedquist, B. C., and Liao, K.-J.: Investigating ambient ozone formation regimes in neighboring cities of shale plays in 
the Northeast United States using photochemical modeling and satellite retrievals, Atmos. Environ., 142, 152-170, https://doi.org/10.1016/j.atmosenv.2016.06.058, 2016.

Chang, J. S., Brost, R. A., Isaksen, I. S. A., Madronich, S., Middleton, P., Stockwell, W. R., and Walcek, C. J.: A three-dimensional Eulerian acid deposition model: Physical concepts and formulation, J. Geophys. Res., 92, 14681, https://doi.org/10.1029/JD092iD12p14681, 1987.

Chauhan, A. and Singh, R. P.: Decline in $\mathrm{PM}_{2.5}$ concentrations over major cities around the world associated with COVID-19, Environ. Res., 187, 109634, https://doi.org/10.1016/j.envres.2020.109634, 2020.

Chen, F. and Dudhia, J.: Coupling an Advanced Land SurfaceHydrology Model with the Penn State-NCAR MM5 Modeling System. Part I: Model Implementation and Sensitivity, Mon. Weather Rev., 129, 569-585, https://doi.org/10.1175/15200493(2001)129<0569:CAALSH>2.0.CO;2, 2001.

CNEMC - China National Environmental Monitoring Center: http: //www.pm25.in, last access: 25 June 2021.

Emery, C., Liu, Z., Russell, A. G., Odman, M. T., Yarwood, G., and Kumar, N.: Recommendations on statistics and benchmarks to assess photochemical model performance, J. Air Waste Manage., 67, 582-598, https://doi.org/10.1080/10962247.2016.1265027, 2017.

Eskes, H., van Geffen, J., Boersma, K. F., Eichmann, K.U., Apituley, A., Pedergnana, M., Sneep, M., Veefkind, P. J., and Loyola, D.: Sentinel-5 precursor/TROPOMI Level 2 Product User Manual Nitrogen dioxide, available at: https://sentinel.esa.int/documents/247904/2474726/ Sentinel-5P-Level-2-Product-User-Manual-Nitrogen-Dioxide (last access: 25 June 2021), 2019.

Georgoulias, A. K., van der A, R. J., Stammes, P., Boersma, K. F., and Eskes, H. J.: Trends and trend reversal detection in 2 decades of tropospheric $\mathrm{NO}_{2}$ satellite observations, Atmos. Chem. Phys., 19, 6269-6294, https://doi.org/10.5194/acp19-6269-2019, 2019.

Github: USEPA/CMAQ, available at: https://github.com/USEPA/ CMAQ/tree/4.7.1, last access: 25 June 2021.

He, G., Pan, Y., and Tanaka, T.: The short-term impacts of COVID19 lockdown on urban air pollution in China, Nature Sustainability, 3, 1005-1011, https://doi.org/10.1038/s41893-020-0581y, 2020.

Hertel, O., Berkowicz, R., Christensen, J., and Hov, Ø.: Test of two numerical schemes for use in atmospheric transportchemistry models, Atmos. Environ. A-Gen., 27, 2591-2611, https://doi.org/10.1016/0960-1686(93)90032-T, 1993.

Hong, S.-Y., Dudhia, J., and Chen, S.-H.: A Revised Approach to Ice Microphysical Processes for the Bulk Parameterization of Clouds and Precipitation, Mon. Weather Rev., 132, 103-120, https://doi.org/10.1175/15200493(2004)132<0103:ARATIM>2.0.CO;2, 2004.

Hong, S.-Y., Noh, Y., and Dudhia, J.: A new vertical diffusion package with an explicit treatment of entrainment processes, Mon. Weather Rev., 134, 2318-2341, https://doi.org/10.1175/MWR3199.1, 2006.

Huang, X., Ding, A., Gao, J., Zheng, B., Zhou, D., Qi, X., Tang, R., Wang, J., Ren, C., Nie, W., Chi, X., Xu, Z., Chen, L., Li, Y., Che, F., Pang, N., Wang, H., Tong, D., Qin, W., Cheng, W., Liu, W., Fu, Q., Liu, B., Chai, F., Davis, S. J., Zhang, Q., and He, K.:
Enhanced secondary pollution offset reduction of primary emissions during COVID-19 lockdown in China, Natl. Sci. Rev., 8, nwaa137, https://doi.org/10.1093/nsr/nwaa137, 2021.

Jang, Y., Lee, Y., Kim, J., Kim, Y., and Woo, J.-H.: Improvement China Point Source for Improving Bottom-Up Emission Inventory, Asia-Pac. J. Atmos. Sci., 56, 107-118, https://doi.org/10.1007/s13143-019-00115-y, 2020.

Kain, J. S.: The Kain-Fritsch Convective Parameterization: An Update, J. Appl. Meteorol., 43, 170-181, https://doi.org/10.1175/15200450(2004)043<0170:TKCPAU>2.0.CO;2, 2004.

Kang, Y.-H., You, S., Bae, M., Kim, E., Son, K., Bae, C., Kim, Y., Kim, B.-U., Kim, H. C., and Kim, S.: The impacts of COVID-19, meteorology, and emission control policies on $\mathrm{PM}_{2.5}$ drops in Northeast Asia, Sci. Rep., 10, 22112, https://doi.org/10.1038/s41598-020-79088-2, 2020.

Kim, H., Lee, S.-M., Chai, T., Ngan, F., Pan, L., and Lee, P.: A Conservative Downscaling of Satellite-Detected Chemical Compositions: $\mathrm{NO}_{2}$ Column Densities of OMI, GOME-2, and CMAQ, Remote Sens.-Basel, 10, 1001, https://doi.org/10.3390/rs10071001, 2018.

Kim, H. C., Lee, P., Judd, L., Pan, L., and Lefer, B.: OMI $\mathrm{NO}_{2}$ column densities over North American urban cities: the effect of satellite footprint resolution, Geosci. Model Dev., 9, 1111-1123, https://doi.org/10.5194/gmd-9-1111-2016, 2016.

Kim, H. C., Kim, S., Kim, B.-U., Jin, C.-S., Hong, S., Park, R., Son, S.-W., Bae, C., Bae, M., Song, C.-K., and Stein, A.: Recent increase of surface particulate matter concentrations in the Seoul Metropolitan Area, Korea, Sci. Rep., 7, 4710, https://doi.org/10.1038/s41598-017-05092-8, 2017a.

Kim, H. C., Kim, E., Bae, C., Cho, J. H., Kim, B.-U., and Kim, S.: Regional contributions to particulate matter concentration in the Seoul metropolitan area, South Korea: seasonal variation and sensitivity to meteorology and emissions inventory, Atmos. Chem. Phys., 17, 10315-10332, https://doi.org/10.5194/acp-1710315-2017, 2017b.

Kim, H. C., Kim, S., Lee, S. H., Kim, B. U., and Lee, P.: Fine-Scale Columnar and Surface $\mathrm{NO}_{x}$ Concentrations over South Korea: Comparison of Surface Monitors, TROPOMI, CMAQ and CAPSS, Inventory, 11, 101, https://doi.org/10.3390/atmos11010101, 2020.

Kong, S. F., Li, L., Li, X. X., Yin, Y., Chen, K., Liu, D. T., Yuan, L., Zhang, Y. J., Shan, Y. P., and Ji, Y. Q.: The impacts of firework burning at the Chinese Spring Festival on air quality: insights of tracers, source evolution and aging processes, Atmos. Chem. Phys., 15, 2167-2184, https://doi.org/10.5194/acp15-2167-2015, 2015.

Lamsal, L. N., Martin, R. V., Padmanabhan, A., van Donkelaar, A., Zhang, Q., Sioris, C. E., Chance, K., Kurosu, T. P., and Newchurch, M. J.: Application of satellite observations for timely updates to global anthropogenic $\mathrm{NO}_{x}$ emission inventories, Geophys. Res. Lett., 38, L05810, https://doi.org/10.1029/2010GL046476, 2011.

Li, J., Nagashima, T., Kong, L., Ge, B., Yamaji, K., Fu, J. S., Wang, X., Fan, Q., Itahashi, S., Lee, H.-J., Kim, C.-H., Lin, C.Y., Zhang, M., Tao, Z., Kajino, M., Liao, H., Li, M., Woo, J.H., Kurokawa, J., Wang, Z., Wu, Q., Akimoto, H., Carmichael, G. R., and Wang, Z.: Model evaluation and intercomparison of surface-level ozone and relevant species in East Asia in the con- 
text of MICS-Asia Phase III - Part 1: Overview, Atmos. Chem. Phys., 19, 12993-13015, https://doi.org/10.5194/acp-19-129932019, 2019.

Li, K., Jacob, D. J., Liao, H., Shen, L., Zhang, Q., and Bates, K. H.: Anthropogenic drivers of 2013-2017 trends in summer surface ozone in China, P. Natl. Acad. Sci. USA, 116, 422-427, https://doi.org/10.1073/pnas.1812168116, 2019.

Li, L., Li, Q., Huang, L., Wang, Q., Zhu, A., Xu, J., Liu, Z., Li, H., Shi, L., Li, R., Azari, M., Wang, Y., Zhang, X., Liu, Z., Zhu, Y., Zhang, K., Xue, S., Ooi, M. C. G., Zhang, D., and Chan, A.: Air quality changes during the COVID-19 lockdown over the Yangtze River Delta Region: An insight into the impact of human activity pattern changes on air pollution variation, Sci. Total Environ., 732, 139282, https://doi.org/10.1016/j.scitotenv.2020.139282, 2020.

Li, M., Zhang, Q., Kurokawa, J.-I., Woo, J.-H., He, K., Lu, Z., Ohara, T., Song, Y., Streets, D. G., Carmichael, G. R., Cheng, Y., Hong, C., Huo, H., Jiang, X., Kang, S., Liu, F., Su, H., and Zheng, B.: MIX: a mosaic Asian anthropogenic emission inventory under the international collaboration framework of the MICS-Asia and HTAP, Atmos. Chem. Phys., 17, 935-963, https://doi.org/10.5194/acp-17-935-2017, 2017.

Liu, F., Page, A., Strode, S. A., Yoshida, Y., Choi, S., Zheng, B., Lamsal, L. N., Li, C., Krotkov, N. A., Eskes, H., van $\operatorname{der}$ A, R., Veefkind, P., Levelt, P. F., Hauser, O. P., and Joiner, J.: Abrupt decline in tropospheric nitrogen dioxide over China after the outbreak of COVID-19, Sci. Adv., 6, eabc2992, https://doi.org/10.1126/sciadv.abc2992, 2020.

Liu, Q., Sha, D., Liu, W., Houser, P., Zhang, L., Hou, R., Lan, H., Flynn, C., Lu, M., Hu, T., and Yang, C.: Spatiotemporal Patterns of COVID-19 Impact on Human Activities and Environment in Mainland China Using Nighttime Light and Air Quality Data, Remote Sens.-Basel, 12, 1576, https://doi.org/10.3390/rs12101576, 2020.

Louis, J.-F.: A parametric model of vertical eddy fluxes in the atmosphere, Bound.-Layer Meteorol., 17, 187-202, https://doi.org/10.1007/BF00117978, 1979.

Miyazaki, K., Bowman, K., Sekiya, T., Jiang, Z., Chen, X., Eskes, H., Ru, M., Zhang, Y., and Shindell, D.: Air Quality Response in China Linked to the 2019 Novel Coronavirus (COVID19) Lockdown, Geophys. Res. Lett., 47, e2020GL089252, https://doi.org/10.1029/2020GL089252, 2020.

NASA GES DISC: http://tropomi.gesdisc.eosdis.nasa.gov, last access: 25 June 2021.

NCEP - National Centers for Environmental Prediction/National Weather Service/NOAA/US Department of Commerce: NCEP FNL Operational Model Global Tropospheric Analyses, continuing from July 1999, Research Data Archive at the National Center for Atmospheric Research, Computational and Information Systems Laboratory, updated daily, https://doi.org/10.5065/D6M043C6, 2000.

Otte, T. L. and Pleim, J. E.: The Meteorology-Chemistry Interface Processor (MCIP) for the CMAQ modeling system: updates through MCIPv3.4.1, Geosci. Model Dev., 3, 243-256, https://doi.org/10.5194/gmd-3-243-2010, 2010.

Pinder, R. W., Adams, P. J., and Pandis, S. N.: Ammonia Emission Controls as a Cost-Effective Strategy for Reducing Atmospheric Particulate Matter in the Eastern United States, Environ.
Sci. Technol., 41, 380-386, https://doi.org/10.1021/es060379a, 2007.

Quanying, Z.: Covid-19 is making it harder to grow food in China, The Economist, available at: https://www.economist.com/china/2020/03/14/ covid-19-is-making-it-harder-to-grow-food-in-china (last access: 25 June 2021), 2020.

Shi, X. and Brasseur, G. P.: The Response in Air Quality to the Reduction of Chinese Economic Activities During the COVID-19 Outbreak, Geophys. Res. Lett., 47, e2020GL088070, https://doi.org/10.1029/2020GL088070, 2020.

Skamarock, W. C. and Klemp, J. B.: A time-split nonhydrostatic atmospheric model for weather research and forecasting applications, J. Comput. Phys., 227, 3465-3485, https://doi.org/10.1016/j.jcp.2007.01.037, 2008.

van Geffen, J. H. G. M., Eskes, H. J., Boersma, K. F., Maasakkers, J. D., and Veefkind, J. P.: TROPOMI ATBD of the total and tropospheric $\mathrm{NO}_{2}$ data products, S5P-KNMI-L2-0005-RP, issue 1.4.0, 6 Feburary 2019, S5P-Knmi-L2-0005-Rp, (1.4.0), 1-76, available at: https://sentinel.esa.int/documents/247904/2476257/ Sentinel-5P-TROPOMI-ATBD-NO2-data-products (last access: 25 June 2021), 2019.

Wang, P., Chen, K., Zhu, S., Wang, P., and Zhang, H.: Severe air pollution events not avoided by reduced anthropogenic activities during COVID-19 outbreak, Resour. Conserv. Recy., 158 104814, https://doi.org/10.1016/j.resconrec.2020.104814, 2020.

Wang, Q. and Su, M.: A preliminary assessment of the impact of COVID-19 on environment - A case study of China, Sci. Total Environ., 728, 138915, https://doi.org/10.1016/j.scitotenv.2020.138915, 2020.

Worldometer: COVID-19 Coronavirus Pandemic, available at: https://www.worldometers.info/coronavirus/ (last access: 25 June 2021), 2020.

WRF: WRF Source Codes and Graphics Software Download Page, available at: https://www2.mmm.ucar.edu/wrf/users/download/ get_sources.html, last access: 25 June 2021.

Xu, K., Cui, K., Young, L.-H., Wang, Y.-F., Hsieh, Y.-K., Wan, S., and Zhang, J.: Air Quality Index, Indicatory Air Pollutants and Impact of COVID-19 Event on the Air Quality near Central China, Aerosol Air Qual. Res., 20, 1204-1221, https://doi.org/10.4209/aaqr.2020.04.0139, 2020.

Yamartino, R. J.: Nonnegative, Conserved Scalar Transport Using Grid-Cell-centered, Spectrally Constrained Blackman $\mathrm{Cu}-$ bics for Applications on a Variable-Thickness Mesh, Mon. Weather Rev., 121, 753-763, https://doi.org/10.1175/15200493(1993)121<0753:NCSTUG>2.0.CO;2, 1993.

$\mathrm{Yu}, \mathrm{S}$.: China's farmers fear food shortages after coronavirus restrictions, Financial Times, available at: https://www.ft.com/ content/cafb828e-6423-11ea-b3f3-fe4680ea68b5 (last access: 25 June 2021), 2020.

Zhang, Q., Jiang, X., Tong, D., Davis, S. J., Zhao, H., Geng, G., Feng, T., Zheng, B., Lu, Z., Streets, D. G., Ni, R., Brauer, M., van Donkelaar, A., Martin, R. V., Huo, H., Liu, Z., Pan, D., Kan, H., Yan, Y., Lin, J., He, K., and Guan, D.: Transboundary health impacts of transported global air pollution and international trade, Nature, 543, 705-709, https://doi.org/10.1038/nature21712, 2017. 
Zhang, R., Zhang, Y., Lin, H., Feng, X., Fu, T.-M., and Wang, Y.: $\mathrm{SO}_{2}$ Emission Reduction and Recovery during COVID-19 in East China, Atmosphere-Basel, 11, 433, https://doi.org/10.3390/atmos11040433, 2020.
Zhang, W. and Xiong, T.: The coronavirus will delay agricultural export surges promised in trade deal with China, The Conversation, available at: https://theconversation.com/thecoronavirus-will-delay-agricultural-export-surges-promisedin-trade-deal-with-china-132227 (last access: 25 June 2021), 2020 . 